\title{
OFFICIAL COMMUNICATIONS
}

\author{
Meetings of The Society
}

\section{New YoRK City, February 27, 1943.}

Abstracts must have been in the hands of Associate Secretary T. R. Hollcroft, 531 West 116th St., New York, N. Y., not later than January 30, 1943. By invitation of the Program Committee there will be an address by Professor Nathan Jacobson entitled Some topics in the theory of semi-linear transformations.

Due to the cancellation of the scientific program for the Annual Meeting, the address by Professor Deane Montgomery on Transformation groups and spheres will be given at this meeting.

\section{New York City, April 23-24, 1943.}

Abstracts must be in the hands of Associate Secretary T. R. Hollcroft, 531 West 116th St., New York, N. Y., not later than March 26. Abstracts received by February 1 will appear in the March issue of this Bullerin. By invitation of the Program Committee there will be addresses by Professor R. H. Cameron on Spectral theory and Professor Nelson Dunford on Absolutely convergent trigonometric sums.

\section{Chicago, Illinois, April 23-24, 1943.}

Abstracts must be in the hands of Associate Secretary W. L. Ayres, Purdue University, Lafayette, Ind., not later than March 26. Abstracts received by February 1 will appear in the March issue of this Bulletin. By invitation of the Program Committee Professor Emil Artin will give an address entitled The axiomatic treatment of number theory and class field theory.

\section{Stanford University, California, April 24, 1943.}

Abstracts must be in the hands of Associate Secretary A. D. Michal, California Institute of Technology, Pasadena, Calif., not later than March 27. Abstracts received by February 1 will appear in the March issue of this BuLLETIN. By invitation of the Program Committee, Professor A. E. Taylor will deliver an address entitled Analysis in complex Banach spaces. There will be a symposium on applied mathematics.

Corvallis, Oregon, June 16-17, 1943.

New Brunswick, New Jersey, September, 1943.

J. R. KLINE, Secretary of the Society.

Articles for insertion in the Bulletin should be typewritten, double spaced, and the author should keep a complete copy. Papers in algebra and theory of numbers should be sent to SAUNDERS MACLANE, 474 Widener, Harvard University, Cambridge, Mass.; in analysis to L. M. GravEs, University of Chicago, Chicago, Ill.; in other fields to P. A. SMrTH, Columbia University, New York, N. Y. Reviews should be sent to VIRGIL SNYDer, Brown University, Providence, R. I., and items for Notes to Bulletin of The Ambrican Mathematical Society, 531 West 116th St., New York, N. Y. All other communications to the editors should be addressed to the Managing Editor, TOMLINSON FORT, Lehigh University, Bethlehem, Pa.

The initial fees and annual dues of members of the Society (see this Bulletin, May, 1930, p. 322; and September, 1942, Part 2, pp. 89-90) are payable to the Treasurer of the Society, B. P. GrLL, 531 West 116th St., New York, N. Y. 


\section{CONTENTS}

\section{Vol. 49, No. 2 FEBRUARY, 1943 Whole No. 521}

On the convergence of sequences of linear operations. By R. P. BAILEY . . . . . . . . . . . . . . . 63

On the approximation of functions by sums of orthonormal functions. By E. N. OBERG.................... 68

Double coset matrices and group characters. By J. S. Frame..

The zeros of certain composite polynomials. By MORRIS MARDEN..................................

On the extension of a vector function so as to preserve a Lipschitz condition. By F. A. Valentine . ............. 100

A family of functions and its theory of contact. By J. F. Ritr. . 109

A convergence theorem for certain Lagrange interpolation

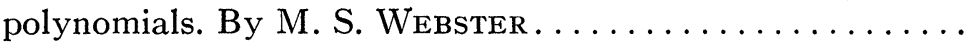

A note on complementary subspaces in a Riemannian space. By Y. C. Wong........................... 120

On the join of two complexes. By C. E. Clark.......... 126

A mixed boundary value problem. Some remarks on a problem of A. Weinstein. By A. E. Heins. . . . . . . . . . . . . . 130

On the convergence of a continued fraction. By T. F. Glass and WALter Leighton.......................... 133

Expansions of quadratic forms. By Rufus Oldenburger.... 136

Sections of continuous collections. By J. H. RoBerts and Paul Civin................................ 142

Functional topology. By Marston Morse............ 144

Recurrence formulas for certain divisor functions. By D. H. LehMer............................... 150

On particular solutions of linear partial differential equations. By K. L. Nielsen and B. P. Ramsay . . . . . . . . . . 156

Residue theorems of harmonic functions of three variables. By Stefan Bergman........................ 163 